\title{
MEHANIČKO-STRUKTURNA ANALIZA ZAVARENOG SPOJA MIKROLEGIRANOG ČELIKA DOBIJENOG SAMOZAŠTITNOM ŽICOM
}

\author{
Radica Prokić Cvetković ${ }^{1}$ \\ Olivera Popović ${ }^{\text {, }}$ \\ Radomir Jovičić, \\ Nenad Milošević1, \\ Dragan Cvetković3
}

\author{
1 Univerzitet u Beogradu, \\ Mašinski fakultet, \\ Beograd, Srbija \\ 'Univerzitet u Beogradu, \\ Inovacioni centar, \\ Beograd, Srbija \\ 3Univerzitet Singidunum, \\ Fakultet za informatiku i računarstvo, \\ Beograd, Srbija
}

\begin{abstract}
Rezime:
Unapređenje tehnologije zavarivanja mikrolegiranih čelika prati razvoj postupaka zavarivanja, od prvobitno korišćenog ručnog elektrolučnog zavarivanja obloženom elektrodom, preko zavarivanja u zaštiti smeše gasova koristeći punu elektrodnu žicu ili punjenu elektrodnu žicu sa metalnom ispunom, pa do najnovijeg postupka zavarivanja punjenom samozaštitnom elektrodnom žicom. Osavremenjavanje postupaka zavarivanja direktno utiče na produktivnost i kvalitet zavarenih spojeva. U ovom radu prikazana je mehaničko-strukturna analiza zavarenog spoja mikrolegiranog čelika primenom samozaštitne žice. Mikrolegirani čelik je zavaren samozaštitnom žicom i isečeni su uzorci za ispitivanja tvrdoće i metalografska ispitivanja. Na osnovu dobijenih rezultata, utvrđena je zavisnost između mikrostrukture i tvrdoće zavarenog spoja.
\end{abstract}

Ključne reči:

zavarivanje, mikrolegirani čelik, samozaštitna žica, tvrdoća, mikrostruktura.
Correspondence:

Radica Prokić Cvetković

e-mail:

rprokic@mas.bg.ac.rs

\section{UVOD}

Mikrolegirani čelici su dosta zastupljeni u procesnoj industriji, a koriste se za izradu cevovoda, cilindričnih i sfernih rezervoara za skladištenje gasova i derivata nafte. Stoga je potreba za postizanjem visokog kvaliteta zavarenih spojeva kod ovih čelika od ogromnog značaja. Zahvaljujući dobrim mehaničkim karakteristikama, koje se postižu optimizacijom hemijskog sastava, kontrolisanim valjanjem i termomehaničkim postupcima prerade, ovi čelici postepeno potiskuju mnoge do sada upotrebljavane konstrukcione čelike $[1,2]$.

Mehaničke karakteristike zavarenih spojeva mikrolegiranih čelika zavise od mikrostrukture metala šava i zone uticaja toplote [3]. Najpoželjniji oblik mikrostrukture u metalu šava, kod ove vrste čelika, jeste acikularni ferit, jer povoljno utiče na mehaničke karakteristike. Obrazovanje ove mikrostrukture je kompleksna pojava koja zavisi od međudejstva velikog broja faktora. Formiranje različitih morfologija ferita direktno utiče na mehaničke karakteristike zavarenog spoja $[4,5]$. 


\section{EKSPERIMENTALNI REZULTATI}

Kao osnovni materijal za zavarivanje korišćene su čelične ploče izrađene od mikrolegiranog čelika klase
P460NL1, debljine $14 \mathrm{~mm}$. Ovaj čelik namenjen je za izradu posuda pod pritiskom predviđenih za rad na sniženim temperaturama. Hemijski sastav osnovnog materijala prikazan je u Tabeli 1.

\begin{tabular}{cccccccccccc}
\hline \multicolumn{10}{c}{ Hemijski elementi [maseni \%] } \\
\hline $\mathrm{C}$ & $\mathrm{Si}$ & $\mathrm{Mn}$ & $\mathrm{P}$ & $\mathrm{S}$ & $\mathrm{Al}$ & $\mathrm{Ni}$ & $\mathrm{Cr}$ & $\mathrm{V}$ & $\mathrm{Nb}$ & $\mathrm{Ti}$ \\
\hline 0,15 & 0,38 & 1.70 & 0.015 & 0,0021 & 0,031 & 0,63 & 0,037 & 0,099 & 0,038 & 0,004 \\
\hline
\end{tabular}

Tabela 1. Hemijski sastav osnovnog materijala.

Za zavarivanje je korišćena samozaštitna žica. Coreshield 8 je samozaštitna žica namenjena za sve položaje zavarivanja, pri čemu zadržava odlične karakteristike luka i daje lep izgled šava. Sa troskom koja brzo očvršćava i koja zadržava istopljeni metal tokom zavarivanja, idealna je za prinudne položaje zavarivanja. Pošto je samozaštitna, nije potrebna dodatna zaštita gasa. U Tabeli 2 dat je hemijski sastav dodatnog materijala.

\begin{tabular}{cccccccc}
\hline & \multicolumn{5}{c}{ Hemijski elementi [maseni \%] } \\
\cline { 2 - 7 } Dodatni materijal & $\mathrm{C}$ & $\mathrm{Si}$ & $\mathrm{Mn}$ & $\mathrm{P}$ & $\mathrm{S}$ & $\mathrm{Al}$ \\
\hline Coreshield 8 & 0.17 & 0.1 & 0.5 & 0.010 & 0.003 & 0.5 \\
\hline
\end{tabular}

Tabela 2. Hemijski sastav dodatnog materijala.

Ploče mikrolegiranog čelika isečene su gasnim postupkom, a žlebovi pripremljeni brušenjem. Na Slici 1 dat je oblik i dimenzije Y žleba.

Iz ploča zavarenih punjenom samozaštitnom elektrodnom žicom izrađene su epruvete za ispitivanje tvrdoće i epruvete za metalografska ispitivanja. Na epruvetama za ispitivanje tvrdoće cilj je da se ispita tvrdoća osnovnog materijala, tvrdoća metala šava i tvrdoća materijala u okviru zone uticaja toplote.

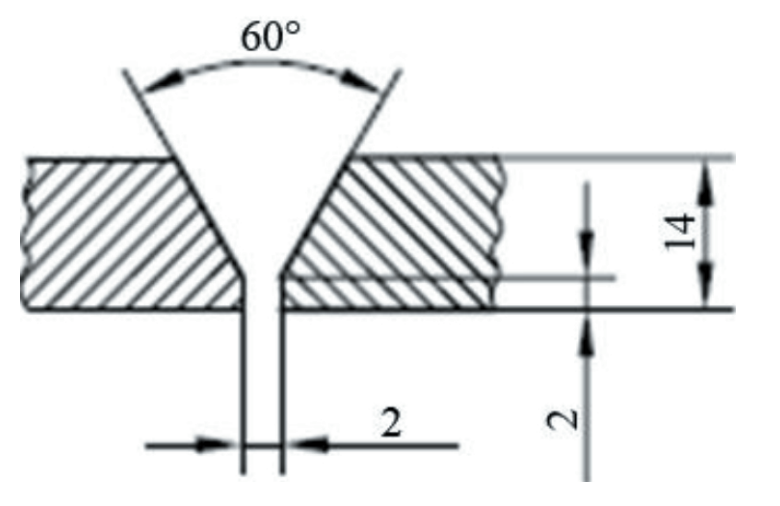

Slika 1. Oblik i dimenzije Y žleba.
Na metalografskim uzorcima je predviđeno da se sprovede svetlosna mikroskopija sa ciljem da se analiziraju mikrostrukture osnovnog materijala, metala šava i materijala obuhvaćenog zonom uticaja toplote.

\section{REZULTATI METALOGRAFSKIH ISPITIVANJA}

Na pripremljenim metalografskim uzorcima izvršen je opšti pregled stanja mikrostrukture na metalografskom (invertovanom svetlosnom) mikroskopu Neophot 21 (Carl Zeiss) i fotografisana su karakteristična mesta. Fotografije mikrostruktura prikazane su na Slikama 2-5.

Mikrostruktura osnovnog materijala je usmerena sitnozrna feritno-perlitna struktura sa ravnomernom veličinom zrna (Slika 2). U zoni pregrevanja koja se nalazi u sklopu zone uticaja toplote uočava se krupnozrna beinitna struktura (Slika 3). Pored zone pregrevanja je zona normalizacije sa veoma sitnozrnom feritno-perlitnom strukturom, što se jasno vidi sa Slike 4 (veličina metalnih zrna je značajno manja od veličine metalnih zrna u osnovnom materijalu). U metalu šava, kako u korenom prolazu, tako i u prolazima popune u centralnoj zoni metala šava (Slika 5) takođe je zastupljena sitnozrna 
feritno-perlitna struktura. Do ovog usitnjavanja strukture došlo je usled uticaja toplote na prethodni prolaz prilikom zavarivanja svakog narednog prolaza popune. $\mathrm{Na}$ licu metala šava, odnosno u završnom prolazu, jasno se vidi prisustvo proeutektoidnog ferita u strukturi, izdvojenog po granicama prvobitno austenitnih zrna, dok je unutar zrna prisutna sitnija feritno-perlitna struktura (Slika 6).

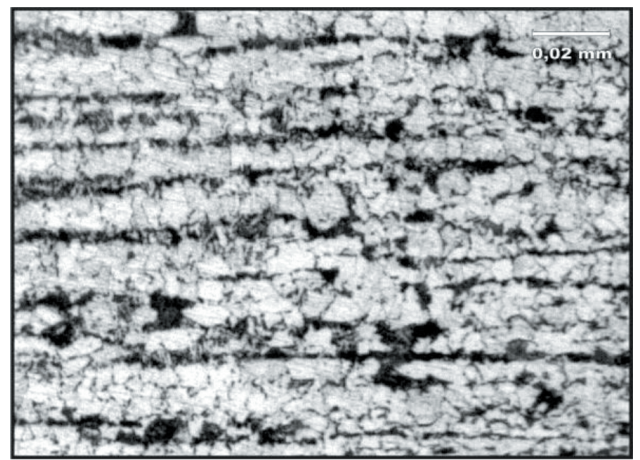

$500 \mathrm{x}$

Slika 2. Mikrostruktura osnovnog materijala.

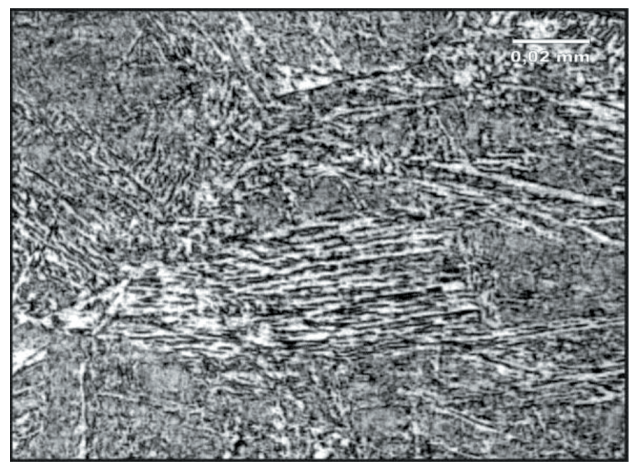

$500 \mathrm{x}$

Slika 3. Mikrostruktura zone pregrevanja u okviru zone uticaja toplote.

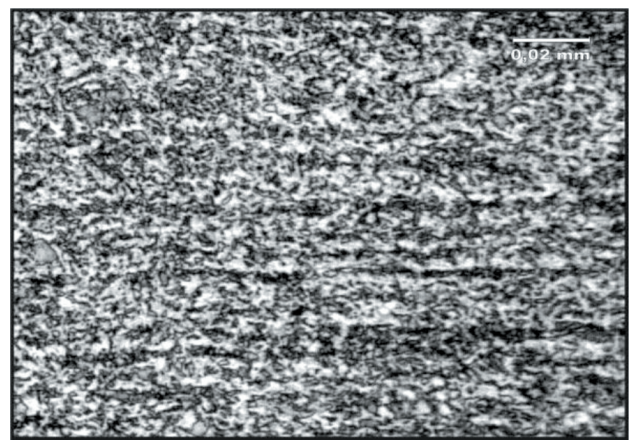

$500 \mathrm{x}$

Slika 4. Mikrostruktura zone normalizacije u okviru zone uticaja toplote.

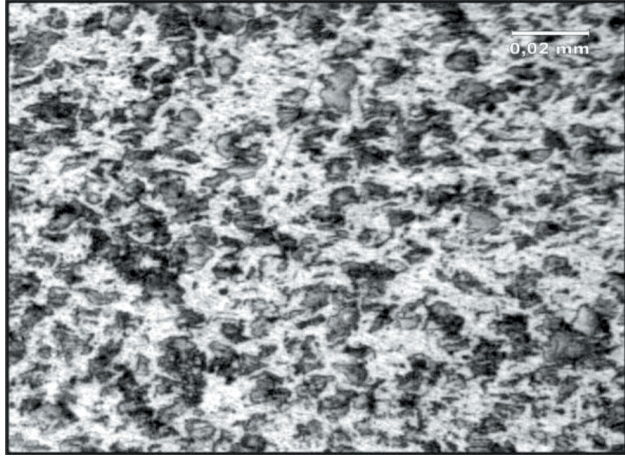

$500 \mathrm{x}$

Slika 5. Mikrostruktura metala šava-koreni prolaz.

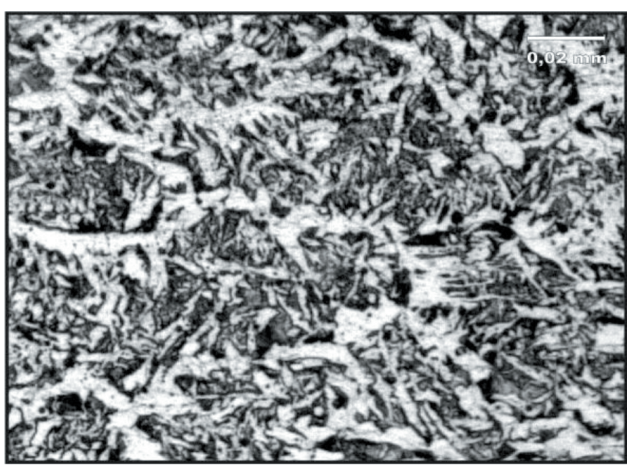

$500 \mathrm{x}$

Slika 6. Mikrostruktura lica metala šava.

\section{REZULTATI ISPITIVANJA TVRDOĆE ZAVARENIH SPOJEVA}

Ispitivanje tvrdoće izvršeno je metodom Vikers. Prilikom ispitivanja korišćena je sila utiskivanja od 98.07 $\mathrm{N}$ i vreme utiskivanja u trajanju od 15 sekundi. Na Slici 7 prikazan je uzorak za ispitivanje tvrdoće, na kome su obeležene merne linije i merna mesta. Uzorak je isečen iz ploče koja je zavarena pomoću punjene samozaštitne topljive elektrodne žice. Rezultati ispitivanja tvrdoće prikazani su na Slikama 8 i 9.

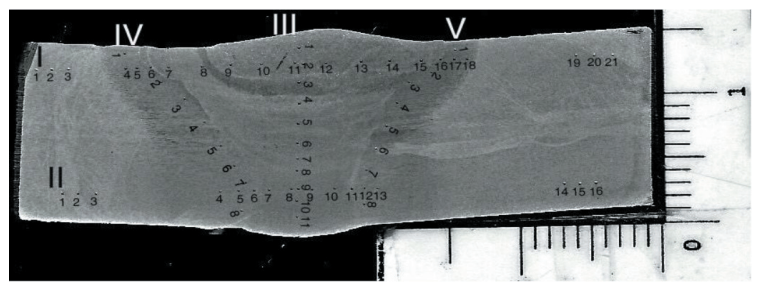

Slika 7. Uzorak za ispitivanje tvrdoće sa obeleženim mernim linijama i mernim mestima. 
Najveće vrednosti tvrdoće izmerene su u zoni uticaja toplote, što je i očekivano, usled prisustva beinita u mikrostrukturi. Tvrdoće izmerene u metalu šava duž pojedinačnih mernih linija ne odstupaju značajno, što je u skladu sa prethodnom konstatacijom da je u metalu šava prisutna ujednačena sitnozrna feritno-perlitna mikrostruktura. Najveće tvrdoće u okviru metala šava izmerene su na licu šava, odnosno u okviru završnog prolaza, zbog grubozrne strukture, dok su prolazi popune i koreni prolazi normalizovani, usled čega su i vrednosti tvrdoće manje.

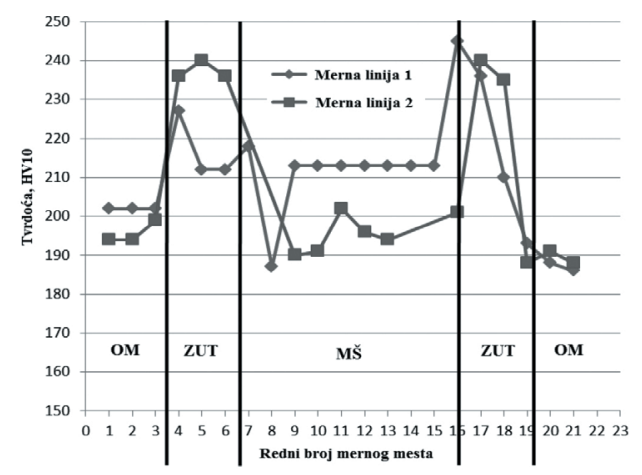

Slika 8. Dijagram raspodele tvrdoće u zavarenom spoju ( OM - osnovni metal, MŠ - metal šava, ZUT - zona uticaja toplote).

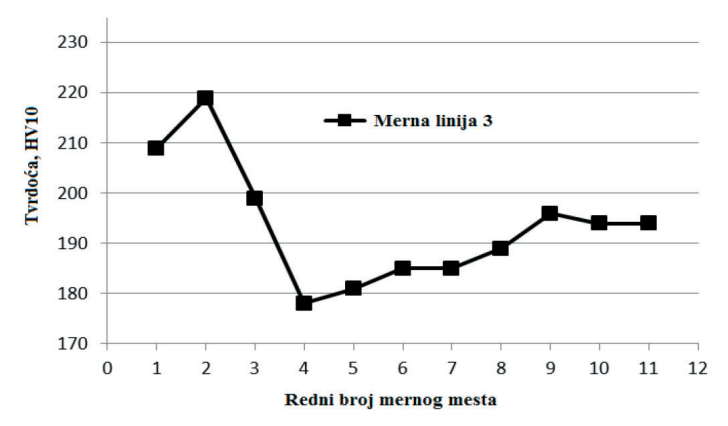

Slika 9. Dijagram raspodele tvrdoće u metalu šava, po debljini zavarenog spoja.

\section{ZAKLJUČAK}

$\mathrm{Na}$ osnovu rezultata sprovedenih ispitivanja moguće je izvesti sledeće zaključke:

- Na osnovu metalografskih ispitivanja određena je struktura osnovnog metala, metala šava i zone uticaja toplote, i uočene su različite morfologije ferita. Na osnovu prisustva, zastupljenosti, rasporeda određenih faza i veličine zrna mogu se objasniti mehaničke karakteristike zavarenih spojeva.

- Usled prisustva krupnozrnog beinita u zoni uticaja toplote izmerene su najveće vrednosti tvrdoće materijala, dok ravnomeran raspored feritno-perlitne strukture u metalu šava zavarenog spoja izrađenog punjenom samozaštitnom žicom rezultuje relativno konzistentnom raspodelom tvrdoće kako po širini, tako i po debljini metala šava. $\mathrm{Na}$ ovakve rezultate značajan uticaj ima količina toplote koja se unosi prilikom izvođenja svakog narednog prolaza popune žleba, jer se na taj način vrši normalizacija prethodno izvedenih prolaza.

- Najmanja tvrdoća izmerena je u središnjoj oblasti metala šava.

- Završni sloj ima značajno veću vrednost tvrdoće u odnosu na slojeve u središnjoj oblasti metala šava. U ovoj oblasti uočavaju se krupnija zrna jer nakon zavarivanja nije vršena termička obrada spojeva.

\section{ZAHVALNOST}

Ovaj rad proistekao je iz rezulatata istraživanja na projektu Ministarstva prosvete, nauke i tehnološkog razvoja Republike Srbije TR 35024.

\section{LITERATURA}

[1] Lukić U., Milosević N., Prokić-Cvetković R., Popović O., Jovičić R., Burzić M., Equations for determination of electric arc parameters for welding with flux-cored self-shielded wire, Proceedings of NANT 2015 2nd International Conference Modern Methods of testing and evaluation in science, Scientific association for development and affirmation of new technologies, Belgrade, 2015, pp.105-110, ISBN 978-86-918415-1-5

[2] Lukić U., Prokić Cvetković R., Popović O., Jovičić R., Impact Of Cooling Rate On The Hardness Of Heat Affected Zone Of Microalloyed Steel P460NL1, 19th International Research/Expert Conference - Trends In The Development Of Machinery And Associated Technology, TMT 2015, Barcelona, Spain, July 2223, 2015, pp. 377-380, ISSN: 1840-4944

[3] Popović O., Prokić Cvetković R., Milošević N., The effects of composition of shielding gas mixture on the microstructure and toughness of microalloyed steel weld metal, Sinteza 2016 - International Scientific Conference on ICT and E-Business Related Research, April 22.2016, Serbia, pp. 226-229, ISBN: 978-86-7912-628-3 
[4] Prokić-Cvetković R., Milosavljević A., Popović O., Kovačević K., Nastanak i osobine različitih oblika ferita u metalu šava niskougljeničnih čelika, Procesna tehnika, Vol. 20, No 4 (2004) str. 48-52.
[5] Prokić-Cvetković R., Milosavljević A., Popović O., Kovačević K., Acikularni ferit u metalu šava niskougljeničnih čelika, Integritet i vek konstrukcija, Vol.5, No 1 (2005), str. 31-43. 